\title{
Influence of Modern Sports Technologies upon Development of the Penitentiary Service Specialists' Physical Qualities
}

\author{
Ihor Donets*, Dmytro Petryk, Yurii Cherezov, Vitalii Honchar, Maksym Kostiuchenko \\ Department of Physical Education, Law Faculty, Academy of the State Penitentiary Service, Chernihiv, 14000, Ukraine
}

Received December 27, 2020; Revised February 1, 2021; Accepted March 12, 2021

\section{Cite This Paper in the following Citation Styles}

(a): [1] Ihor Donets, Dmytro Petryk, Yurii Cherezov, Vitalii Honchar, Maksym Kostiuchenko, "Influence of Modern Sports Technologies upon Development of the Penitentiary Service Specialists' Physical Qualities, "International Journal of Human Movement and Sports Sciences, Vol. 9, No. 2, pp. 308 - 315, 2021. DOI: 10.13189/saj.2021.090219.

(b): Ihor Donets, Dmytro Petryk, Yurii Cherezov, Vitalii Honchar, Maksym Kostiuchenko (2021). Influence of Modern Sports Technologies upon Development of the Penitentiary Service Specialists' Physical Qualities. International Journal of Human Movement and Sports Sciences, 9(2), 308 - 315. DOI: 10.13189/saj.2021.090219.

Copyright $\bigcirc 2021$ by authors, all rights reserved. Authors agree that this article remains permanently open access under the terms of the Creative Commons Attribution License 4.0 International License

\begin{abstract}
The article is devoted to the research of the influence of crossfit classes, as one of the types of modern sports technologies, upon the development of physical qualities of the cadets. Crossfit is quite popular in all over the world and effectively promotes the development of all physical qualities of a human being. The main purpose of crossfit training is to improve physical fitness and functionality of the cardiorespiratory system. The research was conducted at the Academy of the State Penitentiary Service of Ukraine (Chernihiv) in 2019-2020. The research involved 60 cadets of the academy. Two groups were formed: experimental (EG, $\mathrm{n}=26$ ), the cadets of which were involved into crossfit academy classes (3 times a week), and control (CG, $n=34)$, the cadets of which were trained according to the current system of physical training at the academy. The research of the cadets' physical qualities development was carried out in the following exercises: horizontal bar chin-ups, horizontal bar hip-swing-ups, horizontal bar breast-ups, parallel bar dip-ups, 100-meter race, 3000-meter race. It was established that conducting classes with the use of sets of physical exercises according to "Crossfit" system helped to improve the level of physical fitness of the cadets who attended the classes of the academy. The results of the senior year cadets from the EG were significantly $(p<0.05$ - 0.001) better than in the CG for all researched exercises. The greatest effect of crossfit training was found in the indicators of strength and endurance development of the
\end{abstract}

cadets of the EG. This suggests that the high level of physical qualities development of the cadets i.e. future specialists of the State Penitentiary Service of Ukraine will improve the efficiency of performance of duties and functions during their future service and professional activities.

Keywords Physical Qualities, Crossfit, Penitentiary Service, Cadets

\section{Introduction}

The present stage of national development in pedagogical theory and practice makes provision for modernization and designing of new educational, sports and health-improving technologies for the purpose of the maximum use of physical education great potential. In this regard, as well as due to the change of political and military environment in the country, the role of physical training in the Armed Forces of Ukraine, law enforcement agencies and other uniformed services of Ukraine [1-6] including the State Penitentiary Service of Ukraine as an integral structural element has significantly increased.

The analysis of international and national experience on the specifics of the professional activities of penitentiary service specialists showed that it has a multi-faceted 
nature, characterized by daily irregularities. These specialists have to perform duty assignments in various extreme, climatic and geographical conditions, which complicates the performance of their assigned difficult functions: supervision and protection of convicts, work on their rehabilitation etc.

It is important to note that the professional activities of penitentiary specialists are daily associated with a high risk to life and health, the need for constant communication with people who have problems with upbringing and human decency, they require constant psychological concentration and vigilance. This leads to emotional exhaustion of the staff, disorders of their health, both physical and mental. In addition to the risk of violence on the part of convicts, their relatives and friends, there is an increased risk of infection with various diseases for staff $[7,8]$. All this requires a high level of development of all physical qualities of penitentiary service specialists and, first of all, their strength qualities and endurance.

Crossfit is one of the types of modern sports and health-improving technologies, which is quite popular in the United States, countries of the European Union and effectively promotes the development of all physical qualities of a human being $[9,10]$. According to many scientists $[11,12]$, crossfit is a system of training that is characterized by high intensity and constant change of exercises. The main purpose of crossfit training is to improve physical fitness, the work of the cardiovascular and respiratory systems, to teach the body to quickly adapt to changing loads. Harmony of physical development, versatile physical training, the ability to perform any task as effectively as possible are the ideology of life in the 21 st century, in which crossfit occupies a significant place.

Studies by many scientists [9-14], which had been focused on the impact of crossfit training on the level of physical fitness and functionality in those who engage in this modern type of training and, in particular, on the performance of military and police, show a significant effect of crossfit on the development of all physical qualities. The main emphasis is made on their strength and endurance. Scientists have noted the improvement of such functional indicators in those who are engaged in crossfit, such as: heart rate, vital capacity of the lungs, the duration of the recovery process, maximum oxygen consumption, physical performance and many others. Moreover, in the studies of V. Yahodzinskyi et al. a close relationship was found between the indicators of the development of physical qualities in the troops of airborne assault troops trained under the crossfit system, and the results of their compliance with the standards of combat and training, as well as the effectiveness of combat missions [14].

The analysis of the literature has shown that a fair number of researches [10-15] have been conducted on the use of crossfit to improve the physical fitness of various segments of the population in many countries, but the issue of physical qualities development among penitentiary service personnel to improve their performance is considered for the first time. This confirms the timely character of our research.

\subsection{The Aim}

The aim of the article is to study the influence of crossfit classes upon development of the primary physical qualities of cadets i.e. future specialists of the State Penitentiary Service of Ukraine.

\section{Materials and Methods}

\subsection{Materials}

The research was conducted at the Academy of the State Penitentiary Service of Ukraine (Chernihiv) in 2017-2020. The research involved 60 male cadets of the academy. Two groups were formed: experimental (EG, $n$ = 26) the cadets of which were involved into crossfit academy classes ( 3 times a week), and control ( $\mathrm{CG}, \mathrm{n}=$ 34) the cadets of which were trained according to the current system of physical training at the academy.

The study involved only male cadets aged 18 to 23 years, who studied in the 1 st - 4th year at the academy. The experiment lasted 4 years. At the beginning of the study, cadets of EG and CG had significantly the same $(\mathrm{p}>0.05)$ level of physical fitness. There was no special selection based on the indicators of physical fitness of cadets for EG. EG was formed at the beginning of the 1st year of training and included cadets who expressed a desire to train crossfit in the hours of sports and mass work, which is held at the academy according to the daily routine three times a week for 1 hour each.

Thus, cadets of EG and CG had the same number of hours of physical training per week: 4 hours ( 2 classes of 2 hours) - physical education classes, 3 hours ( 3 classes of 1 hour) - sports and mass work, 3 hours (6 days for 30 minutes) - morning exercise. The only difference was that the cadets of EG in the hours of sports and mass work were engaged in crossfit under the guidance of a crossfit instructor, and the cadets of CG were engaged in the existing options for sports and mass work in the academy (short distance running, long distance running in gymnastics) under the guidance of instructors of the Department of Physical Education and unit commanders. EG cadets did not take part in crossfit competitions.

In general, the study was conducted in accordance with the research plan of the Department of Physical Education of the Academy of the State Penitentiary Service. The main purpose of the study was to find modern, simple, affordable popular means of physical education to increase the level of physical fitness of future specialists 
of the State Penitentiary Service of Ukraine, improve their functional condition, health and the effectiveness of future professional activities in this case, one of the conditions for choosing the means of physical education was to obtain the maximum training effect in the shortest possible time. In addition, it was important to minimize the separation of cadets from the educational process.

Therefore, based on the research of many scientists, the author's team within the research work of the Department of Physical Education of the Academy substantiated and developed a program of crossfit classes with EG cadets under the guidance of a crossfit instructor in the agenda of the academy - during sports and mass work. The program included training stages (depending on the training courses), means and modes of dosage of physical activity during crossfit classes. The essence of our program is to perform simple and affordable high-intensity exercises for cadets to develop different muscle groups, mainly by circular training. The main positive features of crossfit are its versatility, accessibility for cadets with different levels of physical fitness, ease of exercise (most exercises were performed with their own body weight), variability in the combination of exercises, mainly strength, the possibility of use in time and space.

\subsection{Methods}

Research methods included theoretical analysis and generalization of literature sources, pedagogical observation, testing, methods of mathematical statistics.

Theoretical analysis and generalization of literature sources was used to study the results of scientific research of many scientists on the topic of our article and to compare our results with the conclusions of other experts in this field. We have processed 33 literature sources, including journals that are part of the scientometric databases Scopus, PubMed, Web of Science and others.

Pedagogical observation was used to assess the correctness of crossfit classes with EG cadets during sports and mass work, the rationality of dosing exercise, the quality of exercise techniques, as well as compliance with all necessary conditions and procedures for testing cadets of EG and CG when testing their level of physical fitness.

The testing of the cadets' physical qualities development was carried out in the following exercises: horizontal bar chin-ups, horizontal bar hip-swing-ups, horizontal bar breast-ups, parallel bar dip-ups, 100-meter race, 3000-meter race.

Considering Horizontal bar chin-ups, it should be mentioned that this exercise is designed to test the level of development of cadets' strength qualities. Preparatory position: over-grip hanging on straight arms with straight head and joined legs (or crossed legs). Bending your arms, lift your body in one motion to the position of the "chin above the horizontal bar". Lower to the preparatory position without swaying. It is forbidden: to take the legs back in the preparatory position, to perform swinging and jerky movements of the torso and legs, to bend the legs at the knees. A slight slow deviation of the straight legs forward and the body from a stationary position is allowed. The score is announced after fixing in the preparatory position for at least 1 second and is a permission to continue the exercise.

As for Horizontal bar hip-swing-ups, we state that this exercise is designed to test the level of development of cadets' strength qualities. Preparatory position: over-grip hanging on straight arms with joined legs. Pulling up without jerks and swinging movements, simultaneously raise the legs to the horizontal bar, and turning around it, achieve straight-arms support with straight body and straight head, joined legs, and spread out forefoot. The straight-arms support is fixed until the announcement of the score. Lower to the preparatory position by rolling forward on straight-arms. It is forbidden to hold onto to the horizontal bar with the chin. It is allowed to bend the legs at the knees.

Regarding Horizontal bar breast-ups, it should be emphasized that this exercise is designed to test the level of development of cadets' strength qualities. Preparatory position: over-grip hanging on straight arms with freestyle legs. Pulling up, move one bent arm to support, then the other, fully extending the arms, reach straight-arms support with straight body and straight head, and joined legs. The straight-arms support is fixed until the announcement of the score. Lower to the preparatory position by vertical technique on straight arms. It is forbidden to put shoulders and forearms on the horizontal bar. It is allowed to deviate the body from a stationary position and perform the exercise by achieving straight-arms support.

The exercise of Parallel bar dip-ups is designed to test the level of development of cadets' strength qualities. Preparatory position: straight-arms support on parallel bars with straight body. Bending the arms, lower the straight body into bent-arms support, stretching the arms, return to the preparatory position. The score is announced after the preparatory position fixing and is a permission to continue the exercise. It is forbidden to throw the calves back and bend the legs at the knees. It is allowed to deviate the body from a stationary position.

Concerning 100-meter race, we affirm that this exercise is designed to test the level of development of cadets' speed characteristics and is performed from a high start on a cinder track or level ground with any surface.

In its turn 3000-meter race is designed to test the level of development of cadets' endurance and takes place at the stadium or any level terrain from a side-by-side or staggered start. Start and finish are equipped in one place.

Assessing of the physical exercises was carried out in accordance with the Regulations on the Organization of Professional Training of Junior Enlisted and Command Staff of the State Penitentiary Service of Ukraine by the instructors of the Department of Physical Training of the 
Academy.

The methods of mathematical statistics were applied to correctly process the data and identify the difference between the researched indicators. The results were reported as Mean $\pm \mathrm{SD}$. The authenticity of the difference between the indicators was determined with the help of Student's t-test. The statistical significance for all statistical tests was set at $\mathrm{p}<0.05$. All statistical analyzes were performed with the SPSS software, version 21, adapted to medical and biological researches.

\subsection{Ethical Approval}

The procedure for organizing the research, the stages, the venue, and the permission for the involvement of the cadets in the pedagogical experiment were previously agreed with the Committee on Compliance with Academic Integrity and Ethics of the Academy of the State Penitentiary Service of Ukraine. The Committee consisted of the leading scientists from the number of scientific and pedagogical staff of specialized departments, officers of organization and coordination of educational process unit, the specialists of the intellectual property group, and the speaker of the Parliament of cadet self-government. The prior consented to participate in the experiment was obtained from all the participants.

\section{Results}

Table 1. The level and dynamics of the cadets' strength qualities development in the EG and CG in the process of their training (Mean \pm $\mathrm{SD}$, times)

\begin{tabular}{|c|c|c|c|c|}
\hline \multirow{2}{*}{$\begin{array}{l}\text { Year of } \\
\text { training }\end{array}$} & \multirow[t]{2}{*}{$\mathrm{EG}(\mathrm{n}=26)$} & \multirow[t]{2}{*}{$\mathrm{CG}(\mathrm{n}=34)$} & \multicolumn{2}{|c|}{$\begin{array}{c}\text { Reliability of } \\
\text { deviation }\end{array}$} \\
\hline & & & $\mathrm{t}$ & $\mathrm{p}$ \\
\hline \multicolumn{5}{|c|}{ Horizontal bar chin-ups } \\
\hline $1 \mathrm{st}$ & $11.5 \pm 0.89$ & $11.6 \pm 0.96$ & 0.08 & $\mathrm{p}>0.05$ \\
\hline 2nd & $16.2 \pm 0.82$ & $13.1 \pm 0.92$ & 2,52 & $\mathrm{p}<0.05$ \\
\hline 3 rd & $18.7 \pm 0.75$ & $14.9 \pm 0.87$ & 3.31 & $\mathrm{p}<0.01$ \\
\hline 4 th & $21.6 \pm 0.71$ & $16.1 \pm 0.83$ & 5.04 & $\mathrm{p}<0.001$ \\
\hline \multicolumn{5}{|c|}{ Horizontal bar hip-swing-ups } \\
\hline $1 \mathrm{st}$ & $5.0 \pm 0.77$ & $4.8 \pm 0.81$ & 0.18 & $\mathrm{p}>0.05$ \\
\hline $2 \mathrm{nd}$ & $10.4 \pm 0.75$ & $7.1 \pm 0.83$ & 2.95 & $\mathrm{p}<0.05$ \\
\hline $3 r d$ & $13.8 \pm 0.72$ & $9.7 \pm 0.84$ & 3.71 & $\mathrm{p}<0.001$ \\
\hline 4th & $15.9 \pm 0.69$ & $11.5 \pm 0.82$ & 4.11 & $\mathrm{p}<0.001$ \\
\hline \multicolumn{5}{|c|}{ Horizontal bar breast-ups } \\
\hline $1 \mathrm{st}$ & $3.9 \pm 0.67$ & $3.6 \pm 0.69$ & 0.31 & $\mathrm{p}>0.05$ \\
\hline 2nd & $7.4 \pm 0.65$ & $5.5 \pm 0.64$ & 2.08 & $\mathrm{p}<0.05$ \\
\hline $3 \mathrm{rd}$ & $9.9 \pm 0.64$ & $6.1 \pm 0.67$ & 4.10 & $\mathrm{p}<0.001$ \\
\hline 4 th & $11.7 \pm 0.59$ & $7.6 \pm 0.68$ & 4.55 & $\mathrm{p}<0.001$ \\
\hline \multicolumn{5}{|c|}{ Parallel bar dip-ups } \\
\hline $1 \mathrm{st}$ & $12.6 \pm 1.21$ & $12.1 \pm 1.27$ & 0.29 & $\mathrm{p}>0.05$ \\
\hline 2nd & $19.5 \pm 1.17$ & $16.8 \pm 1.22$ & 1.60 & $\mathrm{p}>0.05$ \\
\hline $3 r d$ & $27.1 \pm 1.09$ & $20.9 \pm 1.19$ & 3.84 & $\mathrm{p}<0.01$ \\
\hline 4 th & $36.6 \pm 1.04$ & $27.9 \pm 1.21$ & 5.45 & $\mathrm{p}<0.001$ \\
\hline
\end{tabular}

Legend: Mean - arithmetical average; $S D$ - standard deviation; $t$ - value of t-test, $p$ - significance of difference between the indicators of the EG and $\mathrm{CG}$
The analysis of the results of horizontal bar chin-ups showed that the indicators of the 1 st year cadets both of the EG and CG did not differ significantly $(p>0.05)$ (Table 1). The EG cadets' results of the 2nd year of training were significantly better than in the CG by 3.1 times $(p<0.05)$, during the 3rd year of training - by 3.8 times ( $p<0.01)$, and during the 4th year of training - by 5.5 times $(p<0.001)$. The results in this exercise in both groups increased significantly during the period of training at the academy: in the CG - by 4.5 times ( $\mathrm{p}$ $<0.01$ ), and in the EG - by 10.1 times ( $\mathrm{p}<0.001$ ), which indicates a significant advantage of crossfit classes compared to the current system of physical training at the academy.

We can observe a similar trend in the horizontal bar hip-swing-ups: the results of the 1st year cadets both of the EG and CG did not differ significantly $(p>0.05)$, and the future years cadets, who were engaged in crossfit show a significantly higher level of strength development. The difference between the indicators of the EG and CG cadets is 3.3 times during the 2 nd year of training, 4.1 times during the $3 \mathrm{rd}$ year of training, 4.4 times during the 4 th year of training $(\mathrm{p}<0.05-0.001)$. The cadets' dynamics analysis in the horizontal bar hip-swing-ups during their period of study at the academy showed that the results increased significantly in both study groups $(p<0.001)$. However, the difference between the indicators of the 4th and the 1st years of training in the CG is 6.7 times, and it is 10.9 times in the EG, which confirms the positive effect of crossfit training to improve the State Penitentiary Service of Ukraine future specialists' strength qualities.

The same trend of results was preserved as in previous strength exercises in respect of the horizontal bar breast-ups - the 2nd year cadets revealed a significant difference between the results of the EG and CG (1.9 times $(\mathrm{p}<0.05))$. The difference increased by 3.8 times ( $\mathrm{p}$ $<0.001$ ), during the $3 \mathrm{rd}$ year of training and up to 4.1 times ( $\mathrm{p}<0.001)$ during the 4 th year of their education. At the same time, during the research period, the results of the horizontal bar breast-ups in both groups significantly improved ( $\mathrm{p}<0.001$ ), but a more pronounced positive effect was revealed in the EG.

The analysis of the results of the EG and CG cadets while doing parallel bar dip-ups showed that starting from the 3rd year of training the strength indicators of the cadets who were engaged in the crossfit section are significantly better than the cadets who were engaged in the current system of physical training. Thus, the 3rd year cadets of the EG showed the results better than in the CG by 6.2 times $(\mathrm{p}<0.01)$, and the 4 th year cadets' results were 8.7 times higher $(p<0.001)$. During the research period, the results in doing parallel bar dip-ups of the cadets representing both groups significantly $(\mathrm{p}<0.001)$ improved, but the difference in the CG cadets of the 4th and 1 st year of training is 15.8 times, and in totals 24 times difference in the EG. This convincingly 
demonstrates the positive impact of crossfit classes upon the development of the cadets' strength qualities.

The analysis of the results of the 100-meter race showed that the results of the 1st year cadets of both researched groups did not differ significantly $(p>0.05)$ (Table 2). The indicators of the development of speed qualities of the EG and CG cadets during the 2nd and 3rd years of training improved compared to the 1 st year of training, but did not differ significantly $(p>0.05)$. The results of the 4th year cadets who trained in the crossfit academy classes were significantly better than in the group of cadets who received training under the current system of physical training by 0.3 seconds $(\mathrm{p}<0.05)$. This indicates the positive impact of crossfit training upon not only the cadets' strength qualities, but also their speed characteristics. The analysis of the dynamics of the cadets' speed qualities during the training period showed that the results of the 100-meter race improved significantly in both study groups - the 4th year cadets showed the best results. However, if the difference between the indicators of the 4th and the 1st year cadets in the CG is 0.7 seconds ( $p<0.001)$, then it is 0.9 seconds in the EG ( $p<0.001)$, which indicates a more pronounced effect of crossfit training, compared with the current system of physical training for the development of speed qualities of the penitentiary service future specialists.

Table 2. The level and dynamics of the cadets' speed qualities and endurance development in the EG and CG in the process of their training (Mean $\pm \mathrm{SD}$, seconds)

\begin{tabular}{|c|c|c|c|c|}
\hline \multirow{2}{*}{$\begin{array}{c}\text { Year of } \\
\text { training }\end{array}$} & EG $(\mathrm{n}=26)$ & CG $(\mathrm{n}=34)$ & \multicolumn{2}{c|}{$\begin{array}{c}\text { Reliability of } \\
\text { deviation }\end{array}$} \\
\cline { 3 - 5 } & \multicolumn{5}{|c|}{100 -meter race } & $\mathrm{p}$ \\
\hline 1st & $14.5 \pm 0.12$ & $14.6 \pm 0.13$ & 0.57 & $\mathrm{p}>0.05$ \\
\hline 2nd & $14.2 \pm 0.11$ & $14.3 \pm 0.12$ & 0.61 & $\mathrm{p}>0.05$ \\
\hline 3rd & $13.9 \pm 0.10$ & $14.1 \pm 0.11$ & 1.35 & $\mathrm{p}>0.05$ \\
\hline 4th & $13.6 \pm 0.09$ & $13.9 \pm 0.11$ & 2.11 & $\mathrm{p}<0.05$ \\
\hline \multicolumn{5}{|c|}{$3000-$ meter race } \\
\hline 1st & $785.2 \pm 8.84$ & $782.9 \pm 8.27$ & 0.19 & $\mathrm{p}>0.05$ \\
\hline 2nd & $761.1 \pm 8.61$ & $771.4 \pm 8.09$ & 0.70 & $\mathrm{p}>0.05$ \\
\hline 3rd & $731.4 \pm 8.27$ & $754.2 \pm 7.98$ & 1.99 & $\mathrm{p}>0.05$ \\
\hline 4th & $717.3 \pm 8.05$ & $742.1 \pm 7.93$ & 2.15 & $\mathrm{p}<0.05$ \\
\hline
\end{tabular}

Legend: Mean - arithmetical average; $\mathrm{SD}$ - standard deviation; $\mathrm{t}$ - value of t-test, $\mathrm{p}$ - significance of difference between the indicators of the EG and $\mathrm{CG}$

The research of the results of the 3000-meter race shows that the indicators of the 1st year cadets of both EG and CG did not differ significantly ( $p>0.05$ ) (Table 2). Despite the fact that the 2nd and 3rd year cadets' level of endurance development who practiced crossfit is better, compared to the results of the cadets who accomplished the current system of physical training, by 10.3 seconds and 22.8 seconds, respectively, but no significant difference between the average results of the studied groups was detected $(p>0.05)$. The 4 th year cadets of the EG showed significantly better results in the 3000-meter race (11 min 57 seconds) than the cadets of the CG (12 min 22 seconds) by 24.8 seconds ( $\mathrm{p}<0.05$ ). The cadets' results in the 3000-meter race of both groups improved significantly $(\mathrm{p}<0.001)$ during the process of education at the academy: in the CG - by 40.8 seconds, and in the EG - by 1 min 08 seconds. This once again confirms the positive impact of crossfit classes upon the development of all physical qualities of the cadets and their level of endurance in particular.

Thus, conducting classes by means of crossfit helped to improve the cadets' level of physical fitness. The results of the senior year cadets of the EG were significantly ( $p$ $<0.05-0.001$ ) better than those of the CG in all tests. This confirms one of the main advantages of crossfit i.e. its versatility in the development of all physical qualities of the cadets, and indicates the positive impact of crossfit classes upon the formation of comprehensive physical fitness of future penitentiary specialists for their service and professional activities.

\section{Discussion}

Despite the complexity and variety of loads in crossfit, experts $[16,17]$ note that this type of fitness is becoming increasingly popular among fans of sports and healthy lifestyles. According to scientists $[9,18,19]$, the main idea of crossfit is the functional orientation of training and, as a consequence, their maximum diversity. Any serviceman or law enforcement officer feeling inclined to the training can use crossfit regardless of the level of initial training, age, gender $[14,20]$. A positive characteristic of crossfit is its versatility, which indicates that, unlike other sports, this type of training is best suited to real life situations, any type of professional and service activities [19]. Scientists [12, 15] claim that crossfit is also an effective training tool for achieving high results in many sports.

The use of crossfit as a means of physical training of servicemen and law enforcement officers has been studied in scientific papers $[9,16]$. Thus, scientists, emphasizing the need to increase the level of enrollees' physical qualities development who desire to enter higher military educational institutions, substantiated the curriculum to improve the cadets' physical fitness by means of crossfit at the stage of initial education. The scientists believe that the introduction of crossfit in training, sporting and mass participation events of the cadets in the period of their initial training will contribute to the comprehensive development of motor skills of the cadets and prepare them for unexpected versatile loads that arise in the process of training and combat activities [16]. The authors in their work [21] developed a technique of forming professionally important qualities and competencies of 
patrol police officers using crossfit means and proved its effectiveness.

The scientists [20] developed a system of crossfit competitions in order to stimulate physical culture and health-improving activities of the cadets of the Ministry of Internal Affairs of Ukraine and to form motivation for their regular physical training. The essence of the competition was that the cadets had to perform as many repetitions as possible for a certain fixed time. According to the results of a number of competitions, the scientists note some positive changes: the competition contributed to the development of strength, endurance and other physical qualities of the cadets (versatility of crossfit); more than $1000 \mathrm{kcal}$ is burned during one training-competition, which contributes to the weight loss of overweight cadets. In addition, crossfit requires cooperation in a team, creating a competitive spirit within the unit, which motivates regular physical exercises.

Our results support the conclusions of many scientists [22-33] as to the positive impact of crossfit training upon the physical fitness of law enforcement officers and servicemen. In addition, the results of our research have significantly expanded the idea of the use of crossfit, as one of the types of modern sports and health-improving technologies, in the physical training of future specialists of the State Penitentiary Service of Ukraine.

\section{Conclusions}

Conducting training sessions based on crossfit helped to improve the level of physical fitness of the cadets who attended the classes of the academy. The results of the senior year cadets from the EG were significantly ( $p$ $<0.05-0.001)$ better than in the CG in all researched exercises.

The greatest effect of crossfit training was found in the indicators of strength development and endurance of the cadets of the EG. Thus, the results of the 4th year cadets of the EG in horizontal bar chin-ups are significantly better than in the CG by 5.5 times; in the horizontal bar hip-swing-ups - by 4.4 times; in the horizontal bar breast-ups - by 4.1 times; in the parallel bar dip-ups - by 8.7 times; in the 3000 -meter race - by 24.8 seconds. This will help to improve the efficiency of performance of duties by future specialists of the State Penitentiary Service of Ukraine.

\section{Disclosure Statement}

No author has any financial interest or received any financial benefit from this research.

\section{Conflict of Interest}

The authors state no conflict of interest.

\section{REFERENCES}

[1] S. D. Burley, J. R. Drain, J. A. Sampson, H. Groeller. "Positive, limited and negative responders: the variability in physical fitness adaptation to basic military training", Journal of Science and Medicine in Sport, Vol.21, No.11, 1168-1172, 2018. doi:10.1016/j.jsams.2018.06.018

[2] K. Prontenko, G. Griban, V. Prontenko, F. Opanasiuk, P. Tkachenko, Ye. Zhukovskyi, Yu. Kostyuk. "Health improvement of cadets from higher military educational institutions during kettlebell lifting activities", Journal of Physical Education and Sport, Vol.18, No.1, 298-303, 2018. doi:10.7752/jpes.2018.01040

[3] O. I. Kamaiev, V. A. Hunchenko, K. V. Mulyk, V. A. Hradusov, S. V. Homanyuk, M. V. Mishyn, O. M. Martynenko, V. P. Shuryaev. "Optimization of special physical training of cadets in the specialty "Arms and Military Equipment" on performing professional military-technical standards", Journal of Physical Education and Sport, Vol.18, Suppl. No.4, 1808-1810, 2018. doi:10.7752/jpes.2018.s4264

[4] Y. P. Sergienko, A. M. Andreianov. "Models of professional readiness of students of higher military schools of the Armed Forces of Ukraine", Physical Education of Students, Vol.6, 66-72, 2013. doi:10.6084/m9.figshare.840507

[5] D. Kyslenko, K. Prontenko, V. Bondarenko, Yu. Iukhno, R. Radzievskii, V. Prontenko, O. Kizyun. "Development of the physical qualities of future specialists in protective activities due to the use of the kettlebell sport during studies", Journal of Physical Education and Sport, Vol.17, No.2, 789-794, 2017. doi:10.7752/jpes.2018.s2159

[6] K. Prontenko, V. Prontenko, V. Bondarenko, S. Bezpaliy, G. Bykova, O. Zeleniuk, V. Dvoretsky. "Improvement of the physical state of cadets from higher educational establishments in the Ukrainian Armed Forces due to the use of the kettlebell sport", Journal of Physical Education and Sport, Vol.17, No.1, 447-451, 2017. doi: 10.7752/jpes.2017.01067

[7] O. O. Fedoruk, I. S. Yakovets, O. A. Bondarenko. "Penitentiary system and human rights". Kyiv, 2016. Retrieved from http://umdpl.info/library/26173/

[8] D. Sedhem, M. Oktigan. "Basics of professional activity of probation staff". Kyiv, 2017. Retrieved from https://i-rc.org.ua/files/posibnyk-probaciy.pdf

[9] A. Galimova, M. Kudryavtsev, G. Galimov, A. Osipov, N. Astaf'ev, T. Zhavner, E. Panov, L. Zakharova, B. Dagbaev, A. Vapaeva, E. Zemba, P. Fedorova. "Increase in power striking characteristics via intensive functional training in CrossFit", Journal of Physical Education and Sport, Vol.18, No.2, 585-591, 2018. doi: 10.7752/jpes.2018.02085

[10] M. J. Gibala, P. J. Gagnon, B. C. Nindl. "Military applicability of interval training for health and performance", Journal of Strength and Conditioning Research, Vol.29, No.Suppl.11, 40-45, 2015. doi: 10.1519/JSC.000000000000 1119

[11] N. Mullins. "CrossFit: Remember what you have learned; 
apply what you know", Journal of Exercise Physiology, Vol.18, No.6, 32-44, 2015. Retrieved from https://www.res earchgate.net/publication/290123696_CrossFit_Remember _what_you_have_learned_apply_what_you_know

[12] A. Osipov, M. Kudryavtsev, K. Gatilov, T. Zhavner, Yu. Klimuk, E. Ponomareva, A. Karnaukhov. "The use of functional training - Crossfit methods to improve the level of special training of athletes who specialize in combat sambo", Journal of Physical Education and Sport, Vol.17, No.3, 2013-2018, 2017. doi: 10.7752/jpes.2017.03201

[13] J. A. Partridge, B. A. Knapp, B. D. Massengale. "An investigation of motivational variables in CrossFit facilities", Journal of Strength and Conditioning Research, Vol.28, No.6, 1714-1721, 2014. doi: 10.1519/JSC.00000000000002 88

[14] V. Yahodzinskyi, O. Kisiliuk, N. Sydorchuk, O. Sokolovskyi, A. Kobetiak, T. Pushkar, A. Nikitin. "Interrelation of physical, professional and combat performance of the future officers engaged in strength sports during studying". International Journal of Applied Exercise Physiology, Vol.9, No.11, 215-221, 2020. Retrieved from http://www.ijaep.com/index.php/IJAE/article/view/1196

[15] K. Prontenko, G. Griban, A. Aloshyna, I. Bloshchynskyi, Zh. Kozina, O. Bychuk, I. Novitska, M. Korchagin. "Analysis of cadets' endurance development at higher military educational institutions during the kettlebell lifting training", Sport Mont, Vol.17, No.2, 3-8, 2019. doi 10.26773/smj.190601

[16] A. Y. Osipov, R. S. Nagovitsyn, F. H. Zekrin, T. V. Fendel, D. A. Zubkov, T. V. Zhavner. "Crossfit training impact on the level of special physical fitness of young athletes practicing judo", Sport Mont, Vol.17, No.3, 9-12, 2019. doi: 10.26773/smj.191014

[17] H. Kyrolainen, K. Pihlainen, J. P. Vaara, T. Ojanen, M. Santtila. "Optimizing training adaptations and performance in military environment", Journal of Science and Medicine in Sport, Vol.21, No.11, 1131-1138, 2018. doi:10.1016/j.jsa ms.2017.11.019

[18] S. Sammito, N. Gundlach, I. Bockelmann. "Correlation between the results of three physical fitness tests (endurance, strength, speed) and the output measured during a bicycle ergometer test in a cohort of military servicemen", Military Medical Research, Vol.12, No.3, 1-6, 2016. doi:10.1186/s40779-016-0083-4

[19] G. Glassman. "Understanding CrossFit", The CrossFit Journal, Vol.56, No.5-6, 2007. Retrieved from http://library.crossfit.com/free/pdf/CFJ_56-07_Understandi ng.pdf

[20] M. Kudryavtsev, A. Osipov, E. Kokova, Yu. Kopylov, S. Iermakov, T. Zhavner, "The possibility of increasing cadets' physical fitness level of the educational organizations of the Ministry of Internal Affairs of Russia with the help of optimal training effects via CrossFit", Journal of Physical Education and Sport, Vol.18, No.5, 2022-2028, 2018. doi:10.7752/jpes.2018.s5300

[21] K. Prontenko, V. Bondarenko, S. Bezpaliy, D. Kyslenko, Yu. Lisnichenko, V. Ollo, A. Aloshyna, O. Bychuk, V. Smirnov. Physical training as the basis of professional activities of patrol policemen, Baltic Journal of Health and Physical
Activity, Vol.12, No.1, 41-53, 2020. doi: 10.29359/BJHPA. 12.1.05

[22] K. Prontenko, G. Griban, T. Liudovyk, L. Kozibroda, P. Tkachenko, Yu. Kostyuk, Ye. Zhukovskyi. "Influence of kettlebell lifting classes on the level of professionally important psychological qualities and the emotional state of cadets from higher military educational institutions", Journal of Physical Education and Sport, Vol.18, Suppl. No.2, 1055-1059, 2018. doi:10.7752/jpes.2018.s2157

[23] S. Chatterjee, T. Chatterjee, D. Bhattacharyya, S. Sen, M. Pal. "Effect of heavy load carriage on cardiorespiratory responses with varying gradients and modes of carriage", Military Medical Research, Vol.26, No.5, 1-7, 2018. doi: https://doi.org/10.1186/s40779-018-0171-8

[24] A. G. Williams. "Effects of basic training in the British Army on regular and reserve army personnel", Journal of Strength and Conditioning Research, Vol.19, No.2, 254-259, 2005. doi:10.1519/15704.1

[25] K. Prontenko, G. Griban, V. Prontenko, V. Andreychuk, P. Tkachenko, Yu. Kostyuk, Ye. Zhukovskyi. "Kettlebell lifting as a means of physical training cadets in higher military educational institution", Journal of Physical Education and Sport, Vol.17, No.4, 2685-2689. 2017. doi:10.7752/jpes.2017.04310

[26] M. Santtila, K. Pihlainen, J. Viskari, H. Kyrolainen. "Optimal physical training during military basic training period", Journal of Strength and Conditioning Research, Vol.29, Suppl. No.11, 154-157, 2015. doi:10.1519/JSC.000 0000000001035

[27] S. Can, E. Demirkan, S. Ercan. "The effects of exercise preferences on body fat and body mass index by self-report", Universal Journal of Educational Research, Vol.7, No.1, 293-297, 2019. doi:10.13189/ujer.2019.070137

[28] O. Mozolev, O. Halus, I. Bloshchynskyi, R. Kovalchuk. "Human resources management of educational development in sphere of physical culture and sports in Ukraine: comparative analysis (1992-2016)", Journal of Physical Education and Sport, Vol.19, No.Suppl.1, 185-192, 2019. doi: 10.7752/jpes.2019.s1028

[29] K. Prontenko, I. Bloshchynskyi, G. Griban, Ye. Zhukovskyi, T. Yavorska, P. Tkachenko, D. Dzenzeliuk, N. Dovgan, S. Bezpaliy, V. Andreychuk. "Formation of readiness of future physical culture teachers for professional activity", Universal Journal of Educational Research. Vol.7, No.9, 1860-1868, 2019. doi: 10.13189/ujer.2019.070903

[30] S. Widiyawati , R. P. Lukodono , A. T. Lustyana, I. A. Pradana. "Investigation of the risk of daily officer work posture based on rapid upper limb assessment (Rula) method", International Journal of Human Movement and Sports Sciences, Vol.8, No.1, 24-31, 2020. doi: 10.13189/saj.2020.080103

[31] K. Prontenko, G. Griban, A. Aloshyna, S. Bezpalyi, T. Yavorska, S. Hryshchuk, P. Tkachenko, D. Dzenzeliuk, I. Bloshchynskyi. "The physical development and functional state as the important components of the students' health", Wiadomości Lekarskie, Vol.72 No.12, part 1, 2348-2353, 2019. doi: 10.36740/WLek201912115

[32] N. K. Bailasha, E. G. Rintaugu, J. Kamau, F. M. Mwangi, C. 
M. Mucheke, M. D. Otieno. "Institutional based reasons for students non-participation in physical activity and sport programs in the Kenyan public universities", International Journal of Human Movement and Sports Sciences, Vol.8, No.1, pp. 17-23, 2020. doi: 10.13189/saj.2020.080102.
[33] R. Bahtra, M. Asmawi, Widiastuti, F. Dlis. "Improved VO2Max: The effectiveness of basic soccer training at a young age," International Journal of Human Movement and Sports Sciences, Vol.8, No.3, pp. 97-102, 2020. doi: 10.13189/saj.2020.080304. 